\title{
DEVELOPMENTAL MODELS OF CHILDHOOD APRAXIA OF SPEECH (CAS)
}

\author{
Ben Maassen ${ }^{1,2,3}$, Lian Nijland $d^{1,3}$ \\ ${ }^{1}$ Medical Psychology; ${ }^{2}$ Paediatric Neurology; ${ }^{3}$ ENT \\ Radboud University Medical Centre, The Netherlands \\ b.maassen@cukz.umcn.nl
}

\section{Short Overview}

Since the critical review by Guyette and Diedrich in 1981 on Developmental Apraxia of Speech (DAS) as a diagnostic entity, many approaches have been suggested to solve the diagnostic problem of differentiating DAS from other childhood speech disorders. Shriberg et al. (1997) extensively discussed diagnostic features and the theoretical perspectives these are based on. The discussion comprises two fundamental issues. The first concerns the underlying speech production model. Although researchers seem to agree that DAS -just as acquired apraxia of speech in adults (AOS)-- is a speech motor disorder, no agreement exists on the demarcation between psycholinguistic and motor control processes. In the terminology of sequential production models: When does phonological encoding end its process, and when do the processes motor planning and motor programming take over? Is it the 'syllabary' that forms the transition between psycholinguistic and motor processes? Related to this modelling question is the issue whether the origin of particular speech phenomena or speech symptoms can be traced to particular stages in speech production. Recently Ziegler (2005) suggested a hierarchical, computational control model for AOS, rather than a sequential model. Such an approach questions the idea that the speech disorder AOS can be located at a particular processing level; it rather suggests that it is the type of information processing (sequencing, combining elements) that is involved across levels of speech production.

The second fundamental issue is related to development. Development is constituted of a continuous process from repetitive and variegated babbling, to single word production and more-word utterances, in which speech motor control interacts with auditory, higherorder representational and information processing capacities. Early phonology is not an abstract representation of contrasts and rules, but very much implemented as auditory, kinesthetic, tactile and articulatory constriction representations or 'reference frames' (Guenther et al., 1998).

Clinical research on these interactive and developmental processes in speech disorders is fragmentary, and conducted from diverse theoretical viewpoints and clinical questions. In this presentation we will review the relevant literature on CAS, argue for the CASsubtype DAS, and present data from our own lab suggesting that a general combinatorial deficit across processing levels underlies DAS.

\section{References}

Guenther, F.H., Hampson, M., \& Johnson, D. (1998). A theoretical investigation of reference frames for the planning of speech movements. Psychological Review, 105, 611-633.

Shriberg, L.D., Aram, D.M., \& Kwiatkowski, J. (1997). Developmental apraxia of speech: I. Descriptive and theoretical perspectives. Journal of Speech and Hearing Research, 40, 273-285.

Ziegler, W. (2005). A nonlinear model of word length effects in apraxia of speech. Cognitive Neuropsycho$\log y, 22,1-21$. 